\title{
Interrelation Between Conceptual and Linguistic Worldviews (Based on the Economic Lexical Item 'CLIENT')
}

\section{Взаємовідношення між концептуальною та мовною картинами світу (на прикладі лексеми економічної сфери КЛІєНТ)}

Lesia Kushmar

Ph.D. in Philology,

Associate Professor

\section{Леся Кушмар}

кандидат філологічних наук, доцент

\section{E-mail: kushmarlesia@gmail.com orcid.org/0000-0003-0407-6267 \\ Researcher ID: B-8773-2019}

\author{
Kyiv National University of \\ Trade and Economics \\ $\triangle 19$, Kyoto Str., Kyiv, \\ Ukraine, 02156
}

Київський національний торговельноекономічний університет $\triangle$ вул. Кіото, 19, м. Київ, Україна, 02156

Original manuscript received June 26, 2018

Revised manuscript accepted March 20, 2019

\begin{abstract}
This article presents a theoretical approach to the concept interpretation "worldview» which expresses human knowledge about environment. The difference between conceptual and linguistic worldviews has been determined. Associative meaning represents the conceptual worldview. Vocabulary definitions reflect the linguistic worldview. To identify main peculiarities in conceptual and linguistic worldviews the lexical item 'CLIENT' was selected according to criteria: contextual conditioning, frequency, information, presence in dictionaries and encyclopedias of different areas, expressing relevant concepts nowadays. 915 respondents took part in the experiment. Obtained results (1,600 reactions) have been processed using statistical methods.
\end{abstract}


The application of modeling allowed creating the associative field structure defining core and periphery. Items representing essential features of the concept form the core; secondary features of the subject form the periphery. The core and periphery combine associative meaning of the item. Comparison of lexical and associative meanings has been made according to algorithm: defining main components in the lexeme structure using structural-semantic principle; calculation of core reactions because the lexicon core of the native speaker reflects the actual worldview; establishment total number of core reactions that are connected with vocabulary; determination the level of lexical and associative meanings' approximation. The economic lexical item 'CLIENT' is on the edge of incomplete coincidence according to association and lexical meanings. This fact allows arguing that the conceptual worldview is more dynamic than linguistic. Changes in reality are reflected in core reactions of the associative field only with time being reflected in the lexical meaning.

Key words: conceptual worldview, linguistic worldview, associative experiment, associative meaning, lexical meaning.

\section{Вступ}

Вивчення понять концеептуальної та мовної картин світу як наукових категорій зумовлено частотою вживання, відсутністю єдиного трактування, а також чіткого розуміння механізмів розвитку цих феноменів у різних груп мовців, ці поняття виражають особливості людського буття та взаємовідносини людини зі світом.

Уявлення людини про предметний та соціальний світ створює основу свідомої діяльності як частини суспільства і як особистості. Людина усвідомлює себе в закономірних вимірах та соціумі. Актуальність дослідження зумовлено взаємодією процесів мислення людини і мови, адже у мовних поняттях та категоріях закріплено результати пізнання людиною світу.

Мета дослідження - виявити особливості фрагмента мовної та концептуальної картини світу лексеми КЛІСНТ на основі зіставлення семантичного й асоціативного значень поняття економічної сфери.

Завдання дослідження полягає у вивченні останніх наукових праць щодо розуміння картин світу та співвідношення мовної й концептуальної; удосконаленні методики вільного асоціативного експерименту; проведенні експерименту; систематизуванні отриманих реакцій; відтворенні асоціативного поля стимульного слова; визначенні лексичного значення аналізованої лексеми; 
зіставленні асоціативного значень із лексичним; виявленні спільного й відмінного в будові мовної та концептуальної картин світу лексеми економічної сфери КЛІЄНТ. Об'єктом дослідження є фрагменти мовної та концептуальної картин світу, реконструйовані способом зіставлення лексичного й асоціативного значень понять економічної сфери. Предметом дослідження є структура асоціативного поля та асоціативне значення концепту економічної сфери КЛІЄНТ.

Оскільки історично першою формою свідомості, у межах якої сформовано картину світу, $\epsilon$ міфологічна, то саме в міфах віддзеркалювалася модель світу. Починаючи від епохи античної філософії й закінчуючи часом створення натурфілософських теорій XIX ст., спроби побудови картини світу відбувалися в руслі філософських досліджень. Картина світу становить центральне поняття концептуалізації людиною світу, показує особливості іiі існування. Поняття картини світу належить до числа фундаментальних, які виражають специфіку людського буття, відносини його зі світом. Картина світу $\epsilon$ результатом усієї діяльності людини. Вона $є$ настільки давньою, наскільки і сама людина.

Б. Серебренников, О. Кубрякова та В. Постовалова визначають картину світу як глобальний образ світу, який лежить в основі світогляду людини, тобто виражає сутнісні властивості світу в розумінні людини, і є результатом іiі духовної діяльності (Серебренников, Кубрякова \& Постовалова, 1988). На думку О. Кубрякової, іще до знайомства з мовою людина певною мірою знайомиться зі світом, пізнає його; завдяки відомим каналам чуттєвого сприйняття світу вона володіє певною інформацією про нього, розрізняє і ототожнює об'єкти свого пізнання. Засвоєння будь-якої нової інформації про світ здійснюється кожним індивідом на базі тієї мови, якою він уже володіє. Створена таким чином система інформації про світ і $є$ сконструйованою ним концептуальною системою (Кубрякова, 1991).

Сучасні погляди на картину світу репрезентують і європейські науковці, зокрема, А. Глаз (Glaz, 2017), I. Стрія (Stria, 2015), К. Відал (Vidal, 2008), К. Фанк (Funk, 2001). Так, А. Глаз, Д. Данахер, П. Лозовський у монографіï «The Linguistic Worldview: Etnolinguistics, Cognition, and Culture», узагальнюючи попередні погляди на картину світу, розглядають ії під кутом етнолінгвістики (Glaz, Danaher \& Łozowski, 2013). К. Відал у науковій праці 
«Wat is een wereldbeeld? (What is a worldview?)» картину світу тлумачить у нерозривному зв'язку із філософськими знаннями (Vidal, 2008). К. Фанк розуміє картину світу як сукупність вірувань щодо фундаментальних аспектів реальності, що впливають на сприйняття, мислення i пізнання. До аспектів реальності він відносить гносеологічні знання (переконання про природу і джерела знань), метафізичні (переконання про кінцеву природу реальності), космологічні (вірування про витоки і природу Всесвіту, життя й особливо людини), телеологічні (переконання про сенс і призначення Всесвіту, його неживих елементів і його мешканців), теологічні (переконання про існування та природу Бога), антропологічні (переконання про природу i призначення людини в цілому) та аксіологічні (переконання що $є$ хорошим і поганим, що правильно і неправильно) (Funk, 2001).

Сучасні філософи та лінгвісти розмежовують мовну й концептуальну картини світу. Концептуальна картина світу - це не лише система понять про сукупність реалій довкілля, але й система смислів, втілена в ці реалії через слова-концепти; мовна ж картина світу - це система взаємопов'язаних мовних одиниць, що відбиває об'єктивний стан речей довкілля і внутрішнього світу людини. Очевидно, концептуальна картина світу багатша, ніж мовна, оскільки у іï творенні беруть участь різні типи мислення, і не все пізнане людиною набуває словесної форми, не все відображається за допомогою мови, і не вся інформація, яка надходить із зовнішнього світу, знаходить вираження в мові. Для отримання мовною одиницею певного статусу і закріплення іiі у мові вона має пройти нелегкий шлях формування, кристалізації, а також випробування часом (Юдко, 2011).

У нашому дослідженні мовна картина світу визначена як така, що сформована на вербальному рівні лексичними засобами мови й відображена в семантичній системі мови. Концептуальна картина становить індивідуалізовані уявлення про світ, представлені в свідомості реципієнта.

\section{Методи та методики дослідження}

Застосування асоціативного експерименту дало змогу отримати емпіричний матеріал (близько 1600 реакцій) на стимульну лексему 
КЛІЄНТ, що виражає актуальні поняття, якими оперує суб'єкт у своєму житті на сучасному етапі соціального розвитку. Вперше критеріями для відбору лексеми КЛІСНТ стали: 1. Контекстуальна зумовленість (зміст лексеми КЛІСНТ розкривається, поглиблюється й уточнюється за допомогою різноманітних контекстів. Воно виступає центром понятійної системи та притягують до себе слова інших систем). 2. Частотність (лексема КЛІСНТ вживається у всіх сферах життя та активно використовується в підручниках, посібниках, Інтернеті та рекламній продукції). 3. Інформаційність (лексема КЛІЄНТ характеризується достатньою насиченістю змісту). 4. Наявність лексеми в десяти і більше словниках та енциклопедіях 3 різних галузей знань (саме в такій літературі акумулюються як загальні, так і специфічні знання для кожної окремої сфери дослідження).

Для проведення вільного асоціативного експерименту нами було застосовано змішану усно-письмову форму: стимул сприймався на слух, реакція записувалася. Після того, як інформанти отримали анкети, експериментатор давав інструкцію зафіксувати графічно ту першу реакцію, що спаде на думку у зв'язку з почутим.

Відповідно до світових стандартів відбору досліджуваних, ми залучили до участі у вільному асоціативному експерименті 915 осіб. До групи опитуваних увійшла вікова категорія 17-30 років, перевагу було віддано студентській аудиторії, тому що формування мовних можливостей майже завершене i змістове наповнення їх (словниковий запас, ієрархічна структура цінностей, прагматичні установки) у більшості людей залишається відносно стабільним протягом усього життя. До участі в асоціативному експерименті було залучено реципієнтів економічних (економісти, фінансисти, аудитори, бухгалтери, менеджери, маркетологи) та технічних спеціальностей (IT сфера, інженери, електрики, механіки), що дало змогу в процесі опитування отримати достовірні результати.

Для обробки зібраного матеріалу використано асоціативний аналіз 3 елементами статистичного методу: виявлення ієрархії частотності реакцій в асоціативному полі кожного зі стимулів; підрахування кількості однакових відповідей і загальної кількості асоціатів на стимул. 3 метою структуризації асоціативного поля вжито метод моделювання. Зіставний метод став засобом для порівняння лексичного й асоціативного значень стимулу. Метод 
компонентного аналізу дав змогу виявити порівнювані структурні елементи в лексичному значенні й асоціативному полі.

\section{Результати та дискусії}

Концептуальна картина світу - це не лише система понять про сукупність реалій довкілля, але й система смислів, що втілюються у ці реалії через слово-знак і слово-концепт. Мовна ж картина світу це польова система взаємопов'язаних мовних одиниць, що через складну систему лінгвістичних і граматичних значень відбиває об'єктивний стан речей довкілля і внутрішнього світу людини, тобто загалом картину світу як таку. Варто зазначити, що і концептуальна, i мовна картини світу взаємопов'язані, хоча й мають певні відмінності. Базисом концептуальної моделі світу $\epsilon$ інформація, що подається в поняттях, а у мовній моделі головними є знання, закріплені за одиницями конкретних мов. Концептуальна модель організована за законами фізичного світу, що робить іiі багатшою та цікавішою, мовна ж - за законами мови. Концептуальна модель світу - універсальна, впорядкована, характеризується стійкістю та системністю, мовна - фрагментарна, більш рухома, відображає постійні зміни в довкіллі. Слід зазначити, що обидві моделі $\epsilon$ способом існування лексики у свідомості носія i допомагають у відтворенні цілісної картини світу (Юдко, 2011).

Концептуальні ознаки виявляються через семантику мови. Концепти репрезентуються словами. Концептуальні уявлення це мультимодальні симуляції, що розподіляються через конкретні системи модальності (Barsalou, 2003). Процес концептуалізації впливає на відтворення мови, яка опановується носієм (Felker, Klockmann \& Jong, 2018). Образна складова концепту корелює 3 перцептивною й когнітивною сторонами концепту як психолінгвістичного феномена, а понятійна складова $\epsilon$ виходом на мовне втілення явища, що розглядається (у цьому плані понятійну сторону концепту можна було б назвати фактуальною) (Карасик \& Слышкин, 2001: 78).

Предметно-образний зміст концепту зводиться до цілісного узагальненого сліду в пам'яті, пов'язаного 3 певним предметом, явищем, подією, якістю (Rosch, 1975). Понятійна сторона концепту - 
це мовна фіксація концепту, його позначення, опис, структура ознак, дефініція, зіставні характеристики цього концепту стосовно того чи іншого ряду концептів, які ніколи не є ізольованими, їхня найважливіша якість - голографічна багатовимірна вбудованість у систему нашого досвіду. Ціннісна сторона концепту - важливість цього психічного утворення як для індивідууму, так і для колективу. Вона $є$ визначальною для того, щоб концепт можна було виділити. Сукупність концептів, що розглядаються під кутом зору цінностей, утворює ціннісну картину світу. У цьому складному ментальному утворенні виділяються найсуттєвіші для певної культури смисли, ціннісні домінанти, сукупність яких і утворює певний тип культури, що підтримується і зберігається в мові (Карасик, 1996: 5). Концепт спирається на «лінгвокультурологічне поле» - ієрархічну систему одиниць, що мають спільне значення й відображають у собі систему відповідних понять культури (Воробьев, 1997: 60). Він наділений певною пам'яттю, вибірково втілюється не тільки в певних мовних одиницях, але і в когнітивних моделях упродовж тривалого періоду розвитку мови (Балашова, 1998: 197).

Концепт - образ, ідеальне утворення, що вийшло за межі слова і є абстракцією високого рівня, - основний елемент концептуальної картини світу. Всі концепти об’єднуються в концептуальну систему, або концептуальну картину світу. Концептуальні системи пов'язані з розумовою діяльністю людини (Новосадська, 2013).

Концепти реалізуються за допомогою лексем, що є носіями мовної картини світу. Концептуальна й мовна картини світу співвідносяться одна 3 одною, як ціле 3 частиною. Мовна картина світу - це частина концептуальної картини, хоча й найбільш суттєва. Водночас мовна картина бідніша, оскільки в утворенні концептуальної беруть участь поряд із мовними, й інші види розумової діяльності, а також у зв’язку 3 тим, що знак завжди неточний і грунтується на будь-якій одній ознаці (Кубрякова, 1991). Деякі вчені вважають, що правильніше говорити не про співвідношення частина - ціле, мова - частина культури, а про взаємопроникнення, взаємозв'язок і взаємодію на тій підставі, що мова $є$ частиною культури, але i культура $є$ тільки частиною мови. Звідси випливає, що мовна картина світу не повністю поглинута концептуальною, якщо під останньою розуміти образ світу, відображений у свідомості людини, тобто світогляд людини, що 
сформувався внаслідок його фізичного досвіду й духовної діяльності. Отже, концептуальна й мовна картини світу тісно взаємопов'язані, знаходяться у стані безперервної взаємодії та беруть свій початок від реального світу, що оточує людину. Саме мовна семантика відкриває шлях зі світу власне мови у світ реальності. Ця ланка в ланцюгу між двома світами супроводжується культурними уявленнями про предмети і явища культурного світу, властиві певному мовленнєвому колективу загалом та індивідуальному носію мови зокрема (Венжинович, 2006). Семантичні зв'язки через асоціації респондентів констатують представники сучасних наукових досліджень (Vivas, Manoiloff, García, Lizarralde \& Vivas, 2019).

Для виявлення збігів та розбіжностей у будові мовної та концептуальної картин світу нами було використано відомості про структуру лексичного й асоціативного значень слів. Продемонструємо це на прикладі лексеми КЛІСНТ. Асоціативне поле стимулу утворюють 1600 реакцій: адвокат* (*збережено орфографію реципієнтів), банк, банку +12 , Бог, в банку +8 , важлива особа, ввічливість, вдалий +1 , вдячна особа, вигідна жилка, вигідна пропозиція, відвідувач +7 , володар, гості, громі +4 , добре, допомога, дохід, друг +2 , жертва, жінка, завжди правий +28 , клієнт +2 , клієнт банку, клієнти +8 , клієнтський +1 , конкурент, контрагент +1 , користувач, красивии, лікарня +2 , лох +2 , люди +1 , люди з якими ведеш справу, людина +244 , людина 3 грошима +32 , людина щцо користується послугами, людина яка хоче щзось придбати, людина яку обслужують, магазин, МедВедик, менеджер, мій, наш, обслужування +1 , особа +39 , особа з якою маєм справу, особа яка споживає, пацієнт +1 , покупещь +186 , посмішка, постійний +1 , постійний відвідувач, потрібна людина +42 , прибуток +1 , продавеиь +1 , продукт, робота +8 , суб'єкт щуо приносить прибуток, товар +1 , Ульяненко, ура, хороша людина, черга, чоловік +2 , шара +1 , я та інші; іншомовні реакції: вежливость, возможность заработать, всегда прав +2 , деньги + 3, доход + 2, заработок мой, источник счастья, клиент созрел, кость, личо в очках, личь, покупающее товар или услуги, личность, обслуживание, объект, покупатель +19 , покупатель услуги, пользование, пользователь, посетитель, поставщик, потребитель +17 , потребитель товаров и услуг, прибыль +4 , работа, сервис, созрел, спрос, субъект которому надаются услуги, 
сфера деятельности, услуга, услуги, участник +1 , физ. лицо, человек +8 та інші; відсутність відповіді: 18.

Вивчення асоціативної структури слова свідчить про те, що вона являє собою таку мікросистему, у якій існує ядро та периферія: у сукупності сем, представлених у слові, виділяють основні, що віддзеркалюють суттєві ознаки денотата, без яких названий об'єкт не існує як такий, і нерівномірні - такі, що віддзеркалюють другорядні ознаки предмета (Золотова, 2005). Ядерна лексика, на думку 3. Попової, несе головне змістове навантаження. Ядро включає найбільш частотну та інформативну лексику (Терехова, 2000: 104). Н. Бутенко у «Словнику асоціативних норм української мови» (Бутенко, 1979: 8) та С. Мартінек в «Українському асоціативному словнику» (Мартінек, 2007) відносять до ядерних такі реакції, що наявні не менш як у десяти інформантів. У нашому дослідженні до ядерних було віднесено реакції, що повторилися більш як 10 разів (табл. 1).

Таблиця 1. Ядро та периферія асоціативного поля стимулу КЛІЄНТ

\begin{tabular}{|c|c|}
\hline ЯДРО & ПЕРИФЕРІЯ \\
\hline 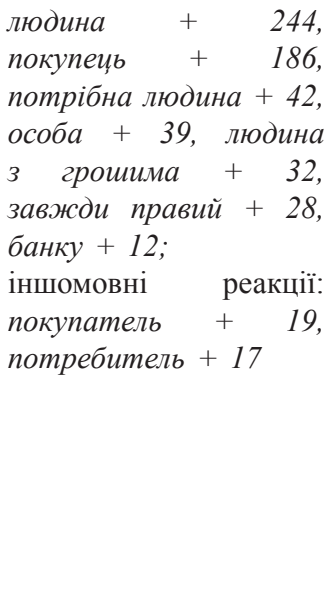 & 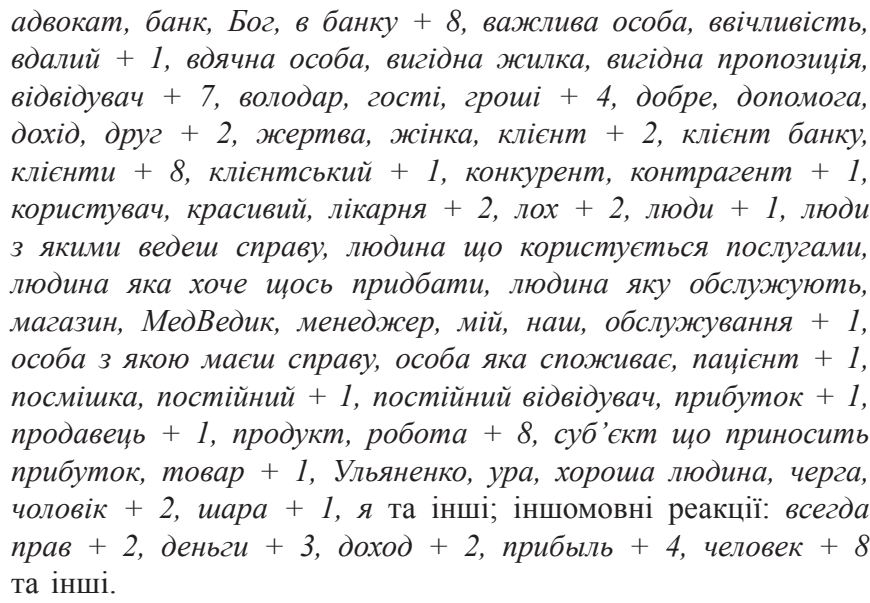 \\
\hline
\end{tabular}

Особливої уваги заслуговує, запропонована О. Загородньою та Т. Недашківською, інформаційно-комп'ютерна система обробки, аналізу й інтерпретації даних асоціативних експериментів «Stimulus», що розробляється як універсальний інструментарій для різновекторних досліджень мовної свідомості, 
зокрема характеристики асоціативного поля (Загородня \& Недашківська, 2015). Ця система відтворює структуру асоціативного поля у вигляді ядра та периферії.

Ядро асоціативного поля кожного стимулу утворюють найбільш активні одиниці (Рис. 1), які вступають у значну кількість різноманітних зв'язків (Залевская, 1979: 64). Ці одиниці характеризуються високою частотністю, елементарністю форми (усі високочастотні одиниці - переважно іменник у називному відмінку), досить загальним значенням (зазвичай, крім категоріальної семи, представлені не більше однієї-двох диференційних ознак).

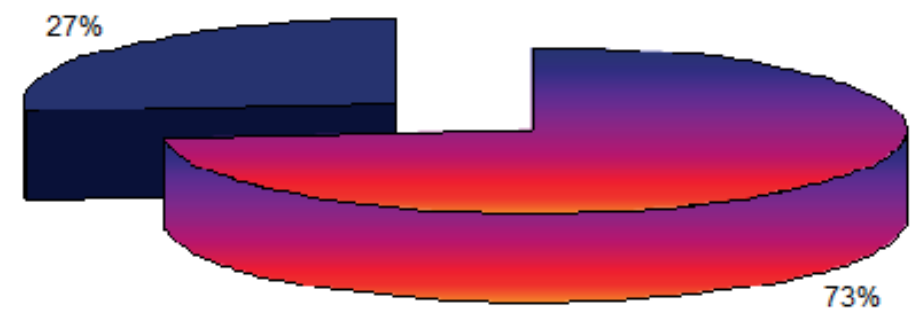

Рис. 1. Співвідношення ядра та периферії асоціативного поля стимулу КЛІСНТ: 1 - ядро (73\%); 2 - периферія (27\%)

Лексичне значення аналізованої лексеми КЛІСНТ зафіксоване у словниках, енциклопедіях та різного роду довідниках: КЛІЄНТ: 1. Особа, що доручила ведення своєї справи адвокатові, нотаріусові тощо. 2. Постійний відвідувач, замовник, покупець i т. ін. || Особа, організація чи установа, що їх обслуговує яка-небудь кредитна, торговельна чи промислова організація (Бусел, 2009: 545-546). 1. Особа, що доручила ведення своєї справи адвокатові, нотаріусові. 2. Постійний відвідувач, замовник, покупець (Куньч, 2005: 362). Людина, з якою ведеться справа, людина, котра платить за послуги (Мочерний, 1995: 128).

Зіставлення лексичного значення 3 асоціативним аналізованого стимулу КЛІСНТ відбувалося за таким алгоритмом: 1. Виділення у структурі лексеми головних компонентів за структурно-семантичним принципом: особа, відвідувач, покупецьь, людина. 2. Підрахунок ядерних реакцій на відповідний стимул, тому що ядро лексикону носія мови відображає актуальну для людини картину світу: 
людина +244, покупець +186 , потрібна людина +42, особа +39 , людина з грошима +32 , завжди правий +28 , банку $+12 ;$ іншомовні реакції: покупатель + 19, потребитель + 17. Загальна кількість ядерних реакцій: 628. 3. Установлення загальної кількості ядерних реакцій, які відповідають словниковому значенню: 543 людина +244, покупець +186 , особа +39 , людина з грошима +32 ; іншомовні реакції: покупатель +19 , потребитель +17. 4. Статистична обробка матеріалу із застосуванням формули: $\frac{A}{B}=C$, де А - загальна кількість ядерних реакцій, В - кількість

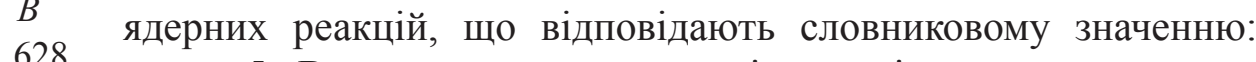
$\frac{628}{543}=1.15$ 5. Визначення належності аналізованого стимулу КЛІЄНТ до групи понять за рівнями наближеності лексичного й асоціативного значень відповідно до формули: якщо $\mathrm{C}=1$, то стимульна лексема належить до першого рівня наближеності - повна відповідність асоціативного значення лексичному; якщо $\mathrm{C}<2$, то стимульна лексема - до другого рівня наближеності (асоціативне значення не в повному обсязі відповідає лексичному); якщо $\mathrm{C}>2, \mathrm{~B}=0$, то стимульна лексема - до третього рівня наближеності (асоціативне значення не відповідає лексичному). Так, $1.15<2$, проте дорівнює майже одиниці, тому стимульну лексему КЛІСНТ варто розглядати на межі між першою (повний збіг асоціативного та лексичного значень) та другою (лексичне та асоціативне значення збігаються не у повному обсязі) групами за рівнем наближеності асоціативного та лексичного значень.

\section{Висновки}

Мова виражає різноманітні картини світу людини, які за допомогою спеціальної лексики відтворені в мові. Мовна картина відображає загальні уявлення про світ, а концептуальна, перебуваючи в тісних зв'язках 3 нею, становить індивідуалізовані уявлення. Формування мовної та концептуальної картин світу взаємно зумовлене. Структуру концептуальної картини світу відтворює система асоціативних зв'язків в асоціативних полях. Мовна картина світу формується засобами лексичного значення слова-поняття. Концепт $є$ ментальним утворенням, його особливість 
полягає в наявності двобічного зв’язку між мовою та свідомістю. Структуру концепту дають можливість відтворити асоціації, які було отримано під час проведення вільного асоціативного експерименту.

Стимульну лексему економічної сфери КЛІЄНТ для асоціативного експерименту вперше було відібрано за такими критеріям: контекстуальна зумовленість; частотність; інформаційність; наявність лексеми в десяти і більше словниках та енциклопедіях $з$ різних галузей знань. 1600 реакцій стали основою для реконструкції асоціативного поля стимульної лексеми у вигляді ядра та периферії. Ядерні реакції віддзеркалюють основні ознаки денотата, без яких об'єкт не існує як такий, їхня кількість в асоціативному полі - десять і більше повторів. Периферійні реакції (з повторюваністю до десяти разів) вказують на другорядні ознаки стимулу. Лексичне значення стимулу представляє відповідний фрагмент мовної картини світу. 3 метою зіставлення мовної та концептуальної картин світу було застосовано алгоритм, що дав змогу виявити взаємовідношення асоціативного та лексичного значень досліджуваної лексеми КЛІЕНТ - асоціативне значення ядерних реакцій не повністю відповідає лексичному значенню. Отримані результати дають можливість стверджувати, що концептуальна картина світу більш динамічна, ніж мовна. Зміна уявлень про реалії насамперед відображається в ядерних реакціях асоціативного поля, лише згодом відбиваючись у лексичному значенні. Лексикографічна фіксація лексичного значення об'єктивно уповільнює процес змін у мовній картині світу. Периферійні реакції асоціативного поля $\epsilon$ своєрідним резервом для трансформації лексичного значення та еволюції мовної картини світу.

Перспектива подальших досліджень передбачає залучення більшої кількості інформантів до участі в асоціативному експерименті та розширення кола лексем економічної сфери 3 метою отримання результатів для виявлення особливостей взаємовідношення мовної та концептуальної картин світу.

\section{Література}

Балашова Л.В. Метафора в диахронии (на материале русского языка XIХХ веков). Саратов, 1998. 216 с.

Бусел В.Т. Великий тлумачний словник сучасної української мови. Київ; Ірпінь: ВТФ «Перун», 2009. 1736 с. 
Бутенко Н.П. Словник асоціативних норм української мови. Ленінград: «Вища школа», 1979. 120 с.

Венжинович Н. Концептуальна й мовна картини світу як похідні етнічних менталітетів. Лінгвістичні студіï. 2006. Вип. 14. С. 8-13.

Воробьев В.В. Лингвокультурология (теория и методы). Москва, 1997. 331 с.

Загородня О.Ф., Недашківська Т.С. Комплексний аналіз стимулів в асоціативному експерименті. Психолінгвістика. Психолингвистика. Psycholinguistics. 2015. Вип. 18(2). С. 41-61.

Залевская А.А. Межъязыковые сопоставления в психолингвистике. Калинин, 1979. $83 \mathrm{c}$.

Золотова Н.О. Ядро ментального лексикона человека как естественный метаязык: автореф. дисс. ... д-ра филол. наук: 10.02.19. Тверь, 2005. 43 с.

Карасик В.И. Культурные доминанты в языке. Языковая личность: культурные кониепты. 1996. С. 3-16.

Карасик В.И., Слышкин Г.Г. Лингвокультурный концепт как единица исследования. Методологические проблемы когнитивной лингвистики. 2001. С. 75-80.

Кубрякова Е.С. Человеческий фактор в языке. Язык и порождение речи. Москва, 1991. $240 \mathrm{c}$.

Куньч 3.Й. Універсальний словник української мови. Тернопіль, 2005. 848 с.

Мартінек С.В. Український асоціативний словник: У 2 т. Т. 1. Від стимулу до реакції. Львів : Видавничий центр ЛНУ імені Івана Франка, 2007. 351 с.

Мочерний С.В. Економічний словник-довідник. Київ, 1995. 368 с.

Новосадська О.Б. Співвідношення мовної та концептуальної картини світу. Наукові записки. 2013. Вип. 33. С. 112-113.

Серебренников Б.А., Кубрякова Е.С., Постовалова В.И. и др. Роль человеческого фактора в языке: Язык и картина мира. Москва, 1988. 215 с.

Терехова Д.І. Особливості сприйняття лексичної семантики слів: Психолінгвістичний аспект. Київ : Київський державний лінгвістичний університет, 2000. 244 с.

Юдко Л.В. Мовна та концептуальна картини світу як відображення свідомості нації. Studia Linguistica. 2011. Вип. 5(2). С. 292-298.

Barsalou, L. (2003). Situated simulation in the human conceptual system. Language and Cognitive Processes, 18, 513-563. https://doi.org/10.1080/01690960344000026

Felker, E., Klockmann, H., \& Jong, N. (2018). How conceptualizing influences fluency in first and second language speech production. Applied Psycholinguistics, 40, 111-136. https://doi.org/10.1017/S0142716418000474

Funk, K. (2001). What is a Worldview? Retrieved from http://web.engr.oregonstate. edu/ funkk/Personal/worldview.html\#whatsNew

Głaz, A. (2017). Worldview as cultural cognition. Language, Mind, Culture, and Society, 1(1), 34-53.

Głaz, A., Danaher, D., \& Łozowski, P. (2013). The Linguistic Worldview: Etnolinguistics, Cognition, and Culture. Berlin: De Gruyter. https://doi. org/10.2478/9788376560748

Rosch, E. (1975). Cognitive Representation of Semantic Categories. Journal of Experimental Psychology, 104, 192-233. https://doi.org/10.1037/00963445.104.3.192

Stria, I. (2015). Towards a Linguistic Worldview for Artificial Languages. Poznań.

Vidal, C. (2008). Wat is een wereldbeeld? (What is a worldview?). Nieuwheid denken. De wetenschappen en het creatieve aspect van de werkelijkheid, 71-85. 
Vivas, L., Manoiloff, L., García, A., Lizarralde, F., \& Vivas, J. (2019). Core Semantic Links or Lexical Associations: Assessing the Nature of Responses in Word Association Tasks. Journal of Psycholinguistic Research, 48, 243-256. https:// doi.org/10.1007/s10936-018-9601-8

\section{References}

Balashova, L.V. (1998). Metafora $v$ diakhronii (na materiale russkogo yazyka XI$X X$ vekov) [Metaphor in diachrony (on the material of the Russian language of the $X I-X X$ centuries)]. Saratov [in Russian].

Busel, V.T. (2009). Velykyi tlumachnyi slovnyk suchasnoi ukrainskoi movy [Big explanatory dictionary of modern Ukrainian language]. Kyiv; Irpin: VTF «Perun» [in Ukrainian].

Butenko, N.P. (1979). Slovnyk asotsiatyvnykh norm ukrainskoi movy [Dictionary of Associative Norms in Ukrainian Language]. Lviv: «Vyshcha shkola» [in Ukrainian].

Venzhynovych, N. (2006). Kontseptualna i movna kartyny svitu yak pokhidni etnichnykh mentalitetiv [Conceptual and linguistic pictures of the world as derivatives of ethnic mentality]. Linhvistychni studii - Linguistic studios, 8-13 [in Ukrainian].

Vorobyev, V.V. (1997). Lingvokulturologiya (teoriya $i$ metody) [Linguoculturology (theory and methods)]. Moscow [in Russian].

Zahorodnia, O.F., \& Nedashkivska, T.Ye. (2015). Kompleksnyi analiz stymuliv $\mathrm{v}$ asotsiatyvnomu eksperymenti [Comprehensive analysis of stimuli in the associative experiment]. Psyholinhvistyka - Psycholinguistics, 18(2), 41-61 [in Ukrainian].

Zalevskaya, A.A. (1979). Mezhyazykovyye sopostavleniya v psikholingvistike [Interlingual juxtaposition in psycholinguistics]. Kalinin [in Russian].

Zolotova, N.O. (2005). Yadro mentalnogo leksikona cheloveka kak estestvennyiy metayazyik [The core of the human mental vocabulary as a natural metalanguage]. Extended abstract of Doctor's thesis. Tver [in Russian].

Karasik, V.I. (1996). Kulturnyye dominanty v yazyke [Cultural dominants in the language]. Yazykovaya lichnost: kulturnyye kontsepty - Language personality: cultural concepts, 3-16 [in Russian].

Karasik, V.I., \& Slyshkin, G.G. (2001). Lingvokulturnyy kontsept kak edinitsa issledovaniya [Linguocultural concept as a unit of study]. Metodologicheskiye problemy kognitivnoy lingvistiki - Methodological problems of cognitive linguistics (pp. 75-80) [in Russian].

Kubryakova, E.S. (1991). Chelovecheskiy faktor v yazyke. Yazyk i porozhdeniye rechi [The human factor in the language. Language and speech generation]. Moscow [in Russian].

Kunch, Z.Y. (2005). Universalnyi slovnyk ukrainskoi movy [Universal Dictionary of the Ukrainian language]. Ternopil [in Ukrainian].

Martinek, S.V. (2007). Ukrayinskyi asotsiatyvnyi slovnyk [Ukrainian associative dictionary]. (Vols. 1-2). Lviv: Vydavnychyi tsentr LNU imeni Ivana Franka [in Ukrainian].

Mochernyi, S.V. (1995). Ekonomichnyi slovnyk-dovidnyk [Economic DictionaryDirectory]. Kyiv [in Ukrainian]. 
Novosadska, O.B. (2013). Spivvidnoshennia movnoi ta kontseptualnoi kartyny svitu [The correlation between the language and the conceptual picture of the world]. Naukovi zapysky - Scientific notes, 33, 112-113. [in Ukrainian].

Serebrennikov, B.A., Kubryakova, E.S., \& Postovalova, V.I. (1988). Rol chelovecheskogo faktora $v$ yazyke: Yazyk $i$ kartina mira [The role of the human factor in the language: Language and the picture of the world]. Moscow [in Russian].

Terehova, D.I. (2000). Osoblyvosti spryiniattia leksychnoi semantyky sliv: Psyholinhvistychnyi aspect [Features of perception of lexical semantics: Psycholinguistic aspect]. Kyiv: Kyivskyi derzhavnyi linhvistychnyi universytet [in Ukrainian].

Yudko, L.V. (2011). Movna ta kontseptualna kartyny svitu yak vidobrazhennia svidomosti natsii [Linguistic and conceptual picture of the world as a reflection of the nation's consciousness]. Studia Linguistica, 5(2), 292-298 [in Ukrainian].

Barsalou, L. (2003). Situated simulation in the human conceptual system. Language and Cognitive Processes, 18, 513-563. https://doi.org/10.1080/01690960344000026

Felker, E., Klockmann, H., \& Jong, N. (2018). How conceptualizing influences fluency in first and second language speech production. Applied Psycholinguistics, 40, 111-136. https://doi.org/10.1017/S0142716418000474

Funk, K. (2001). What is a Worldview? Retrieved from http://web.engr.oregonstate. edu/ funkk/Personal/worldview.html\#whatsNew

Głaz, A. (2017). Worldview as cultural cognition. Language, Mind, Culture, and Society, 1(1), 34-53.

Głaz, A., Danaher, D., \& Łozowski, P. (2013). The Linguistic Worldview: Etnolinguistics, Cognition, and Culture. Berlin: De Gruyter. https://doi. org/10.2478/9788376560748

Rosch, E. (1975). Cognitive Representation of Semantic Categories. Journal of Experimental Psychology, 104, 192-233. https://doi.org/10.1037/00963445.104.3.192

Stria, I. (2015). Towards a Linguistic Worldview for Artificial Languages. Poznań.

Vidal, C. (2008). Wat is een wereldbeeld? (What is a worldview?). Nieuwheid denken. De wetenschappen en het creatieve aspect van de werkelijkheid, 71-85.

Vivas, L., Manoiloff, L., García, A., Lizarralde, F., \& Vivas, J. (2019). Core Semantic Links or Lexical Associations: Assessing the Nature of Responses in Word Association Tasks. Journal of Psycholinguistic Research, 48, 243-256. https:// doi.org/10.1007/s10936-018-9601-8

\begin{abstract}
АНОТАЦІЯ
У статті представлено теоретичний підхід до тлумачення поняття картина світу, яке виражає пізнання людиною навколишнього середовища. Визначено різницю між концептуальною та мовною картинами світу. Концептуальна картина світу представлена концептами свідомості реципієнта. У нашому дослідженні концепт представлений асоціаціями, які отримані під час проведення вільного асоціативного експерименту (1600 реакцій). Мовну картину світу віддзеркалюють словникові дефініції. Відповідно до критеріїв контекстуальної зумовленості, частотності, інформачійності, наявності
\end{abstract}


лексеми в десяти і більше словниках та енциклопедіях різних сфер, стимульною лексемою для виявлення особливостей мовної та концептуальної картин світу відібрано лексему КЛІєНТ, що виражає актуальні поняття сьогодення у різних сферах життя людини. Участь в експерименті взяло близько тисячі опитуваних. Отримані результати оброблено за допомогою статистичних методів. Застосування методу моделювання асоціативного поля дало змогу відтворити структуру асоціативного поля КЛІЕНТ, із визначенням ядра та периферії. Ядро сформоване лексемами, що представляють суттєві ознаки денотата, периферію утворюють другорядні ознаки предмета. ядро та периферія складають асочіативне значення досліджуваної лексеми. Зіставлення лексичного значення з асоціативним відбувалося за алгоритмом: виділення у структурі лексеми головних компонентів за структурносемантичним принципом; підрахунок ядерних реакцій на відповідний стимул, тому що ядро лексикону носія мови відображає актуальну для людини картину світу; установлення загальної кількості ядерних реакцій, які відповідають словниковому значенню; визначення рівня наближеності лексичного й асочіативного значень аналізованого стимулу. Стимульну лексему КЛІєНТ було виявлено на межі неповного збігу асочіативного та лексичного значень, що дало змогу стверджувати, що концептуальна картина світу більш динамічна, ніж мовна. Зміна уявлень про реалії відображається в ядерних реакціях асочіативного поля, лише згодом відбиваючись у лексичному значенні.

Ключові слова: концептуальна картина світу, мовна картина світу, асочіативний експеримент, асочіативне значення, лексичне значення.

\section{Кушмар Леся. Взаимоотношения между концептуальной и языковой картинами мира (на примере лексемы экономической сферы КЛИЕНТ)}

\section{АННОТАЦИЯ}

В статье представлен теоретический подход к толкованию понятия картина мира, которое выражает познания человеком окружающей среды. Определена разница между концептуальной и языковой картинами мира. Концептуальная картина мира представлена концептами сознания реципиента. В нашем исследовании концепт представлен ассоциациями, полученные во время проведения свободного ассоциативного эксперимента (1600 реакций). Языковую картину мира отражают словарные дефиниции. Согласно критериям контекстуальной обусловленности, частотности, информативности, наличии лексемы в десяти и более словарях и энциклопедиях разных срер, для выявления особенностей языковой и концептуальной картин мира стимульной лексемой была отобрана лексема КЛИЕНТ, выражающая актуальные понятия в различных срерах жизни человека. Участие в эксперименте приняли около тысячи респондентов. Полученные результаты обработаны с помощью статистических методов. Применение метода моделирования ассоциативного поля позволило воссоздать структуру ассоциативного поля 
КЛИЕНТ, с определением ядра и периферии. Ядро сформировано лексемами, представляющие существенные признаки денотата, периферию образуют второстепенные признаки предмета. Ядро и перифрерия составляют ассоциативное значение исследуемой лексемы. Сопоставление лексического значения с ассоциативным происходило по алгоритму: выделение в структуре лексемы главных компонентов по структурно-семантическому принципу; подсчет ядерных реакций на соответствующий стимул, потому что ядро лексикона носителя языка отражает актуальную для человека картину мира; установления общего количества ядерных реакций, которые соответствуют словарном значению; определение степени близости лексического и ассоциативного значений рассматриваемого стимула. Стимульную лексему КЛИЕНТ было обнаружено на границе неполного совпадения ассоциативного и лексического значений, что позволило утверждать - концептуальная картина мира более динамична, чем языковая. Изменение представлений о реалиях отображается в ядерных реакциях ассоциативного поля, только потом отражаясь в лексическом значении.

Ключевые слова: концептуальная картина мира, языковая картина мира, ассоциативный эксперимент, ассоциативное значение, лексическое значение. 